\title{
A NEW TECHNIQUE OF ARTERIAL SWITCH OPERATION WITH IN SITU CORONARY REALLOCATION FOR TRANSPOSITION OF GREAT ARTERIES
}

K. S. Murthy, MCh

K. M. Cherian, MS, FRACS
Coronary artery translocation is the most important step in achieving a successful result in arterial switch operations. Although a few centers have reported excellent results, coronary artery transfer requires high technical expertise. We report a new technique of arterial switch operation without coronary translocation. By creating flaps in the proximal great arteries, the coronaries are transferred to the neoaorta without distortion of their original anatomic position. This technique avoids problems related to coronary translocation. Because coronary buttons are not excised, there is no need for nonviable material to be used in reconstruction of neopulmonary artery. Arterial wall is sutured to arterial wall, so postoperative bleeding is lessened. This technique can be used for any type of coronary anomaly and great arterial relationship. Coronary perfusion is well maintained. Two patients with transposition variants and ventricular septal defects have been operated on successfully with this technique. Postoperative investigations showed good coronary perfusion, without right or left ventricular outflow obstruction or leakage through the semilunar valves. This technique achieves anatomic correction for transposition of the great arteries, just as a conventional arterial switch operation does, but it avoids problems related to coronary artery translocation. We believe that it is a much simpler, more reliable, and more reproducible operation than others in current use, and it can be carried out by many cardiac surgeons with acceptable results. The early results are encouraging, although longer follow-up and more cases are essential. (J Thorac Cardiovasc Surg 1996; 112:27-32)
D espite acceptable results with physiologic correction (atrial switch operation) for transposition of the great arteries (TGA), early and midterm results have shown that anatomic correction (arterial switch operation) is superior to physiologic correction. ${ }^{1}$ In 1975, Jatene and coworkers ${ }^{2}$ from Brazil reported the first successful arterial switch operation in a patient with TGA and ventricular septal defect (VSD). Because of the early high mortality associated with arterial switch operations as a result of technical difficulties in coronary arterial transfer,

From the Institute of Cardiovascular Diseases, Madras Medical Mission, Madras, India.

Received for publication Oct. 19, 1995; accepted for publication Dec. 18, 1995.

Address for reprints: K. S. Murthy, MCh, Consultant Cardiac Surgeon, Institute of Cardiovascular Diseases, Madras Medical Mission, 4A, Jayalalitha Nagar, Mogappair, Madras 50, India.

Copyright $(\mathcal{O} 1996$ by Mosby-Year Book, Inc.

$0022-5223 / 96 \$ 5.00+0 \quad \mathbf{1 2 / 1 / 7 1 2 5 9}$ alternative techniques to avoid coronary translocation have been developed. In 1978, Aubert and associates $^{3}$ reported baffling of aortic blood to the coronary arteries through a surgically created aortapulmonary window. Between 1972 and 1976, Damus, ${ }^{4}$ Kaye and Cross, ${ }^{5}$ and Stansel ${ }^{6}$ reported endto-side anastomosis of the proximal pulmonary artery to the ascending aorta with placement of a conduit from right ventricle to distal pulmonary artery. Yacoub and Radley-Smith, ${ }^{7}$ Planché and coworkers, ${ }^{8}$ Castañeda and colleagues, ${ }^{9}$ Takeuchi and Katogi, ${ }^{10}$ and Asou and associates ${ }^{11}$ reported different techniques for translocating the coronary arteries in arterial switch operations. Coronary artery translocation is the most important step in achieving a successful result in arterial switch operations. Although a few centers in the world have reported excellent results, coronary artery transfer continues to require high technical expertise. We believe that our new technique of arterial switch operation with in situ coronary relocation provides 


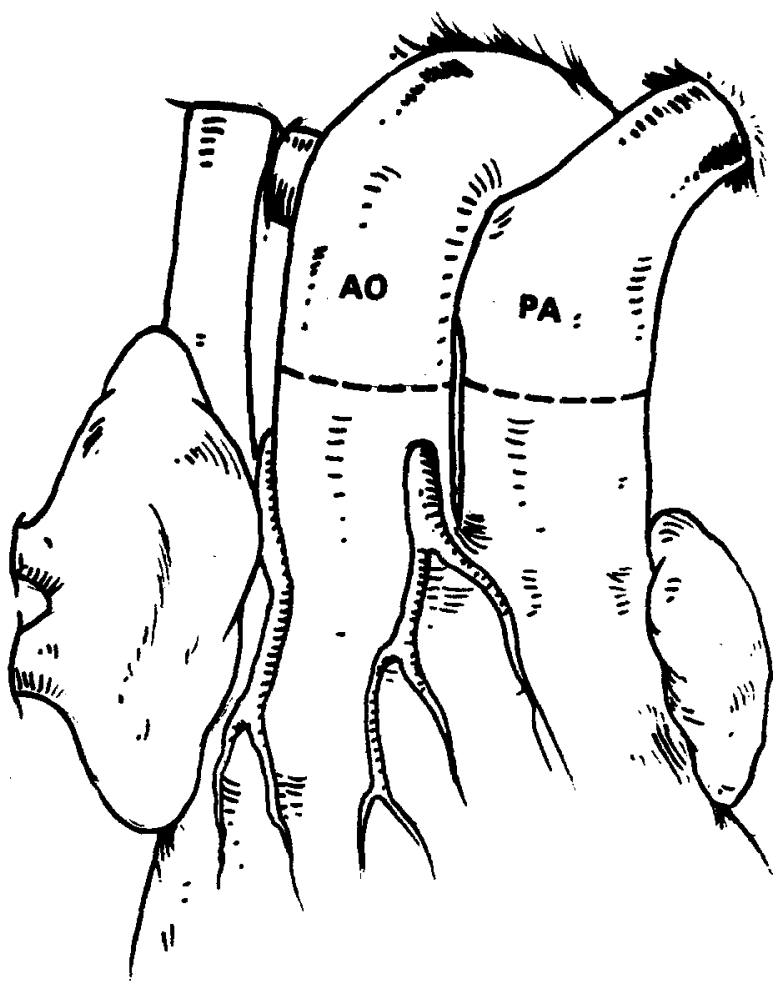

Fig. 1. Diagram illustrating incisions (dashed lines) for division of the great arteries. $A O$, Aorta; $P A$, pulmonary artery.

an alternative to coronary translocation. We report two patients with TGA variants and VSD successfully treated with this technique.

\section{Material and methods}

\section{Case reports}

CASE 1. A 3-month-old baby weighing $3 \mathrm{~kg}$ and with an echocardiographic diagnosis of TGA and VSD was operated on. The aorta was anterior and to the right of the pulmonary artery. It had a usual coronary artery pattern, with left and right coronary arteries arising from the facing sinuses.

CASE 2. A seven-month-old child weighing $5.6 \mathrm{~kg}$ was operated on. Echocardiography, cardiac catheterization, and angiocardiography, revealed double-outlet right ventricle, subpulmonic VSD, and severe pulmonary arterial hypertension. Pulmonary vascular resistance index was 2 Wood units. The aorta was anterior and to the left of the pulmonary artery. The left anterior descending coronary artery was found to arise from facing sinus 1 and the circumflex right coronary arteries were found to arise from facing sinus 2 .

Technique. Cardiopulmonary bypass was achieved with an aortic and single-venous cannula. The ductus was ligated and divided. Cooling was begun to achieve a final core temperature of $18^{\circ} \mathrm{C}$. The main pulmonary artery, including the right and left branch pulmonary arteries, was dissected from the surrounding structures up to the hilum.

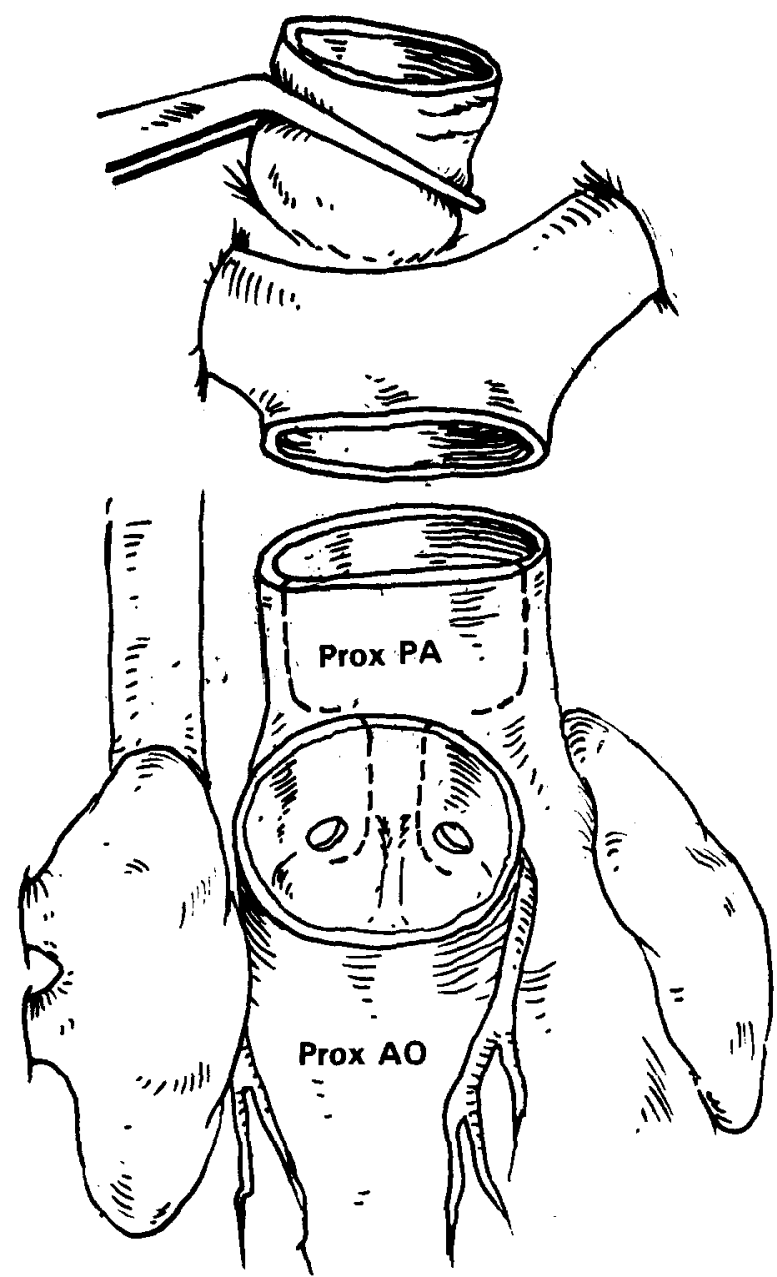

Fig. 2. Diagram illustrating hockey stick-shaped incisions (dashed lines) for making flaps in the proximal great arteries. Prox $P A$, Proximal pulmonary artery; Prox $A O$, proximal aorta.

The aorta was crossclamped and cardioplegia was administered. The aorta was transected approximately $1 \mathrm{~cm}$ downstream from the origin of the coronary arteries. At this stage the ostium, the initial course of the left and right coronary arteries, and the presence of conal branches were identified. The pulmonary artery was then divided just proximal to the bifurcation (Fig. 1). The proximal great arteries were separated from each other, dissecting the periadvential tissue up to the base of the heart. Care was taken to avoid injury to the anomalous coronary artery passing between the great arteries.

A hockey stick-shaped incision was made in the proximal aorta on either side of the commissure, leaving a margin of a few millimeters for suturing the lower part of the aorta from the base. Another hockey stick-shaped incision was made in the proximal pulmonary artery, starting from the middle of the facing sinus on either side (Fig. 2). The lower part of the curved incision should be slightly longer than its aortic counterpart, leaving a margin 


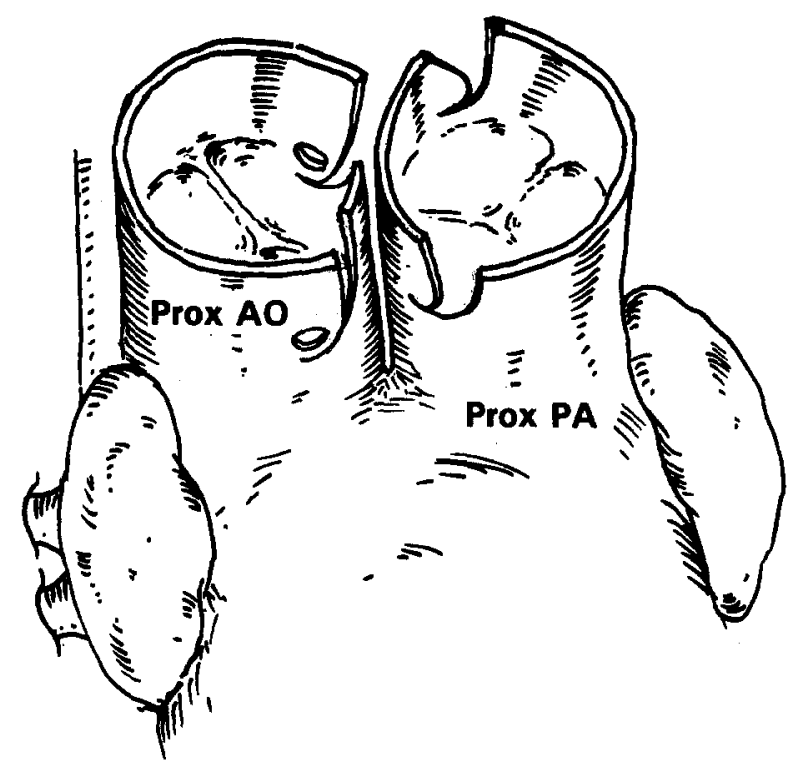

Fig. 3. Diagram illustrating appearance of the flaps after incision in the great arteries. Prox $A O$, Proximal aorta; Prox $P A$, proximal pulmonary artery.

of a few millimeters of pulmonary artery wall from the base for suturing (Fig. 3).

With 7-0 monofilament absorbable double-armed suture, starting from the angles of the incision (end of the incisions) and keeping the inner part of the pulmonary wall in between the aortic incision, the outer flap of aortic wall was sutured to the outer flap of the pulmonary wall with one end of the suture. With the other end of the suture, the inner flap of the pulmonary wall was sutured from inside the aorta, around and away from the coronary ostium (Fig. 4). The same maneuver was repeated on the other side also thus keeping both the coronary ostia committed to the neoaorta with bigger sinuses formed by the pulmonary arterial flaps (Fig. 5, $A$ ). The free edge of the aortic commissure was anchored to the neoaortic wall with interrupted 7-0 Prolene polypropylene sutures (Ethicon, Inc., Somerville, N.J.) with knots on the neopulmonary side (Fig. 5, $B$ ).

After a Lecompte maneuver, the distal aorta was anastomosed to neoaorta with 7-0 monofilament absorbable suture (Fig. 5, $A$ ). The VSD was closed through the right atrium with a polytetrafluoroethylene patch and 5-0 Prolene continuous suture during a brief period of total circulatory arrest. Cardiopulmonary bypass was reinstituted, and the aortic crossclamp was released. Bleeding points from the neoaortic suture lines were secured. During rewarming, the distal pulmonary artery was anastomosed to the proximal neopulmonary artery with 7-0 monofilament absorbable suture; no nonviable tissue was used for reconstruction of the neopulmonary artery (Fig. 6). A common wall for great arteries was located proximally, where they were facing each other, for suturing both the distal aorta and pulmonary artery (Fig. 7).

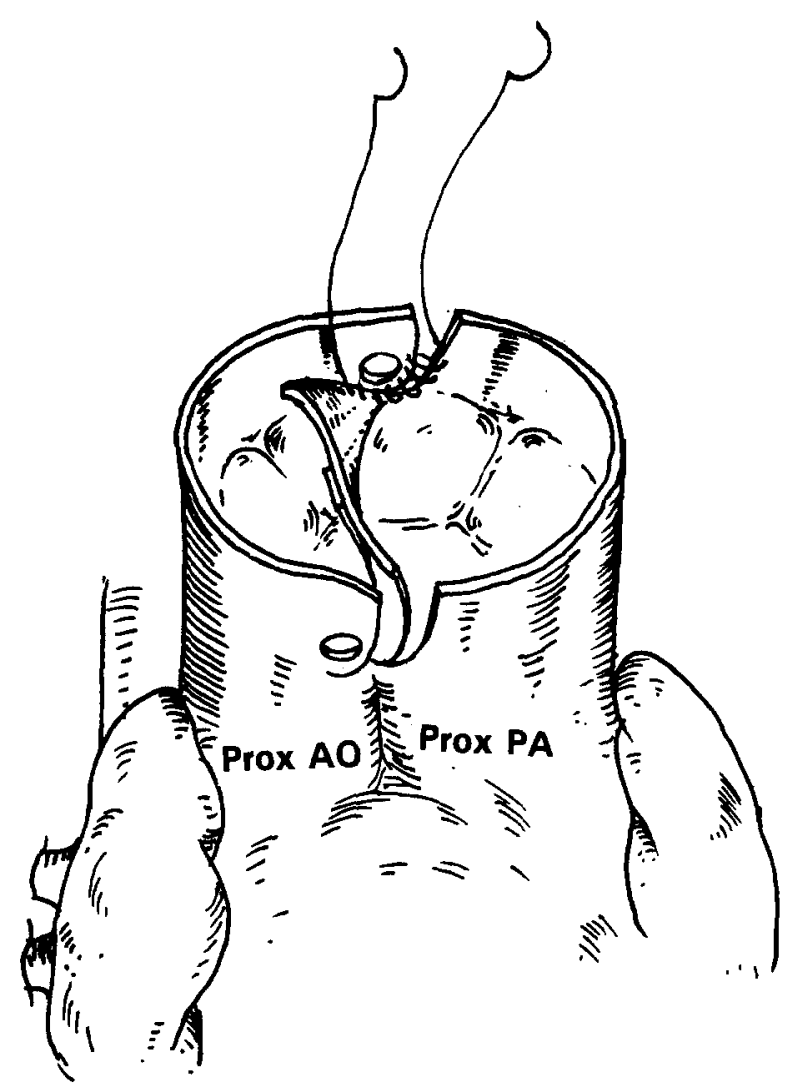

Fig. 4. Diagram illustrating suturing of the flaps in the proximal great arteries. Prox $A O$, Proximal aorta; $\operatorname{Prox} P A$, proximal pulmonary artery.

\section{Results}

Both the patients were weaned from bypass with minimal inotropic support and a left atrial pressure between 4 and $9 \mathrm{~mm} \mathrm{Hg}$. Results of ST-segment monitoring throughout the postoperative period were normal. There was no significant cardiac enzyme rise after operation. Postoperative echocardiography showed neither left ventricular outflow tract nor right ventricular outflow tract obstruction and no leakage through the semilunar valves. Both patients were catheterized after operation; there was no pull-back gradient in either the right ventricular outflow tract or the left ventricular outflow tract and both the coronary arteries filled well with contrast medium (Fig. 8).

\section{Discussion}

The critical part of the arterial switch operation is the transfer of coronary arteries. Any kink or traction of the coronary arteries after translocation is detrimental. There are different types of coronary 


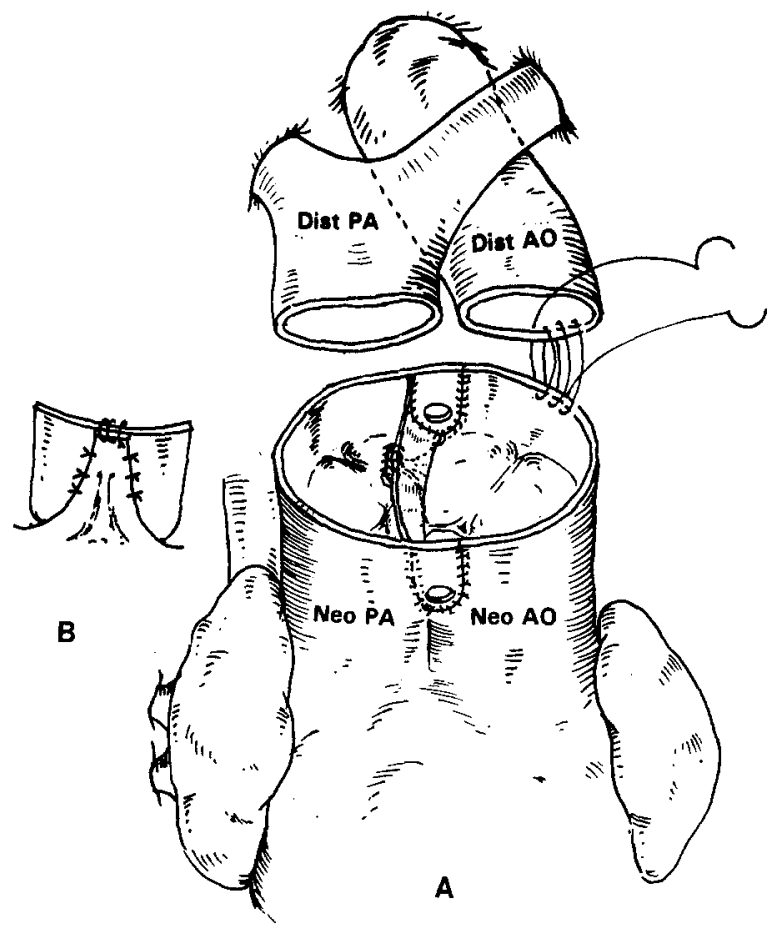

Fig. 5. A, Diagram after completion of sutures in the proximal great arteries and, after Lecompte maneuveur, the suturing of proximal neoaorta to distal aorta (Dist $A O$ ). Dist $P A$, Distal pulmonary artery; $N e O P A$, neopulmonary artery. B, Diagram illustrating anchoring of commissural flap to the neoaortic wall.

anomalies in TGA, with and great arterial relationships that necessitate appropriate techniques for proper alignment of translocated coronary arteries and great arteries.

Yacoub and Radley-Smith ${ }^{7}$ described arterial switch operations for five different coronary anomalies associated with TGA. Planché and coworkers ${ }^{8}$ modified these techniques, performing neopulmonary artery reconstruction with a single large posterior patch of pericardium. Takeuchi and Katogi ${ }^{10}$ described a modification of the Aubert technique ${ }^{3}$ to create an aorta-pulmonary window and reconstruct coronary rerouting. Asou and associates ${ }^{11}$ reported five different types of intramural coronary anatomy and detailed their techniques of coronary transfer.

Most of these techniques require excision of coronary buttons along with dissection of proximal part of the coronary arteries without any injury to the main coronary arteries and their branches. Equivalent U-shaped segments of arterial wall are removed or trapdoor incisions are made in the

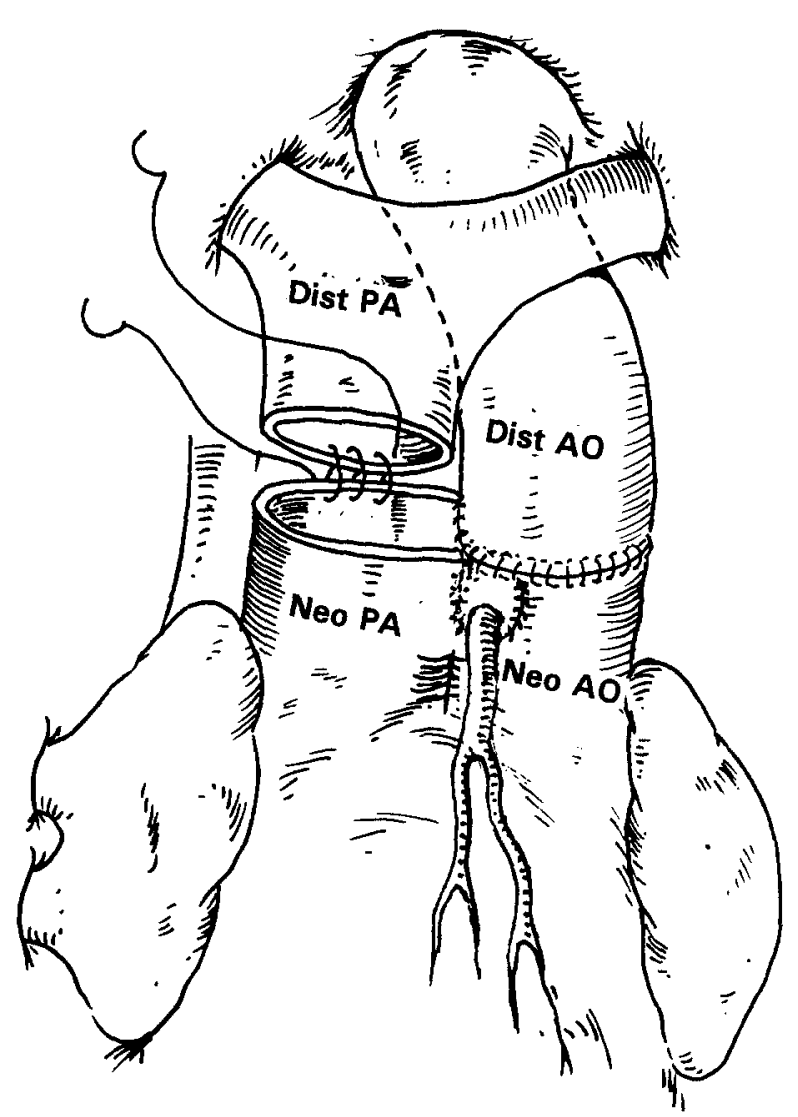

Fig. 6. Diagram illustrating proximal neopulmonary artery (Neo $P A$ ) suturing to distal pulmonary artery (Dist $P A)$ after completion of neoaortic reconstruction. Dist $A O$, Distal aorta; $N e O A O$, neoaorta.

proximal pulmonary artery at the appropriate sites for coronary artery reimplantation. There is thus some chance of kinking or traction during the translocation if it is not performed properly; only relatively few centers in the world have reported excellent results because this procedure is highly demanding technically.

We believe that there is a need for a technical modification that is reproducible and reliable, ensuring that the arterial switch operation can be readily carried out by cardiac surgeons with acceptable results. With our new technique, there is no need for incision of the coronary buttons, nor for the dissection of the proximal coronary arteries and branches. There is no need to translocate the coronary arteries to the neoaorta. Through the creation of flaps in the great arteries, the coronary arteries are transferred to neoaorta without distorting the original anatomic position. This avoids kinking and traction. Suture of the pulmonary arterial wall flap 


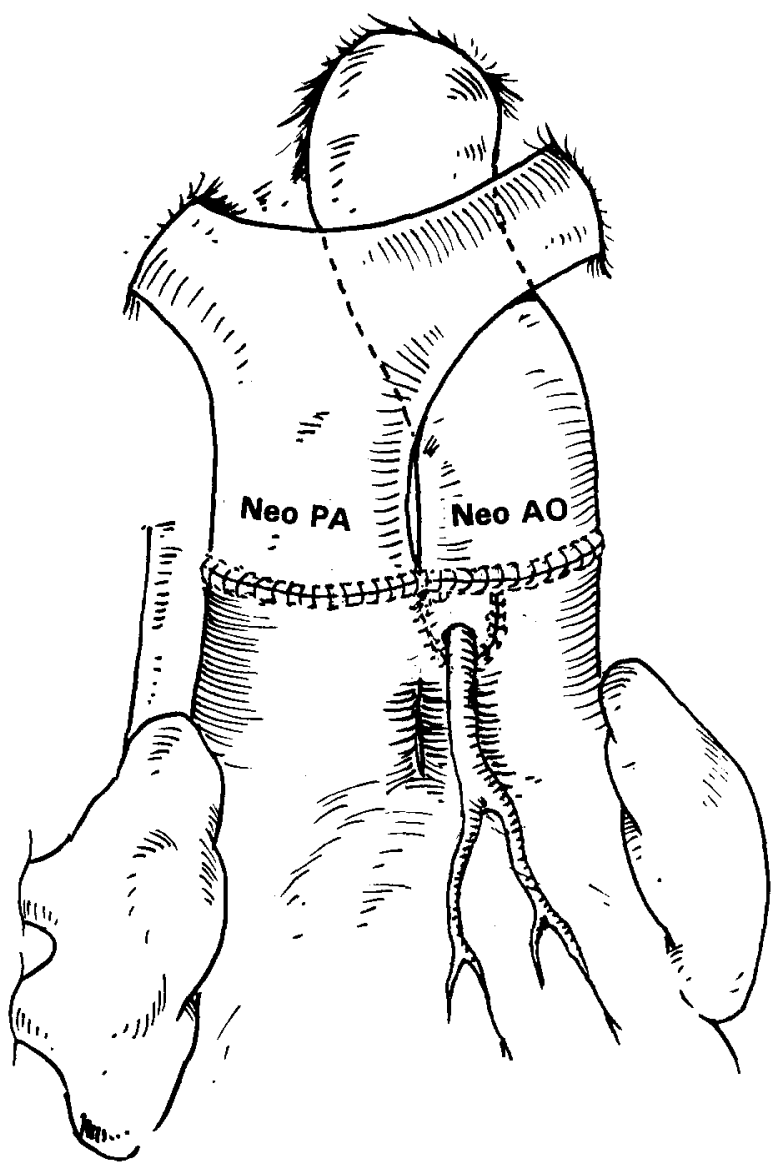

Fig. 7. Diagram illustrating appearance of great arteries after completion of operation. Great arterial relationship shown as side by side or anteroposterior. Cardiopulmonary bypass cannulas not shown for better clarity. Neo $A O$, Neoaorta; Neo $P A$, neopulmonary artery.

inside the aortic wall around the coronary ostia creates larger coronary sinuses (not a tunnel), thereby ensuring maintenance of good coronary perfusion. Because the coronary buttons are not excised, there is no need to use nonviable tissue (pericardium or prosthetic patch) to reconstruct the neopulmonary artery; the arterial growth will therefore be uniform. In this technique, arterial wall is sutured to arterial wall, lessening postoperative bleeding. This technique can be used for any type of coronary anomaly and great artery relationship because the coronary arteries arise from the facing sinuses. There is no compromise in left or right ventricular outflow tract because the baffling is done above the semilunar valves. There is no incompetence of aortic and pulmonary valves, as shown by postoperative echocardiography and angiocardiography. There is reliable coronary perfusion because

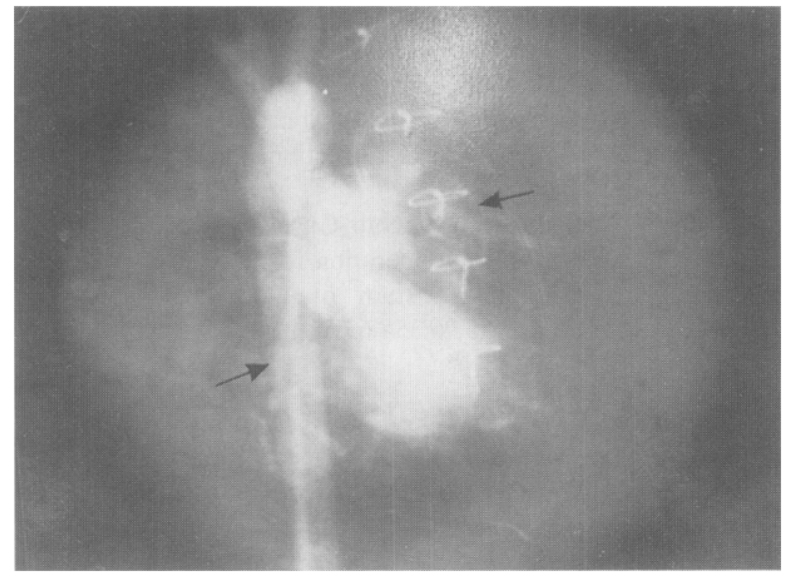

Fig. 8. Postoperative left ventricular angiography showing wide left ventricular outflow tract and coronary arteries.

the coronary arteries are not disturbed from their original anatomic position; this constitutes the most important element of this technique. Postoperative aortic root angiography showed filling of both coronary arteries (Fig. 8). If the baffle is sutured meticulously inside the aorta, baffle leakage can be avoided.

\section{Conclusion}

We believe that this newly described technique is a much simpler, more reliable, and more reproducible operation because there is no need for coronary artery translocation. It achieves anatomic correction of TGA, just as a conventional arterial switch operation does, but it avoids the problems related to coronary artery translocation. The early results are encouraging, although longer follow-up and a greater number of cases are essential.

\section{REFERENCES}

1. Quaegebeur JM, Rohmer J, Ottenkamp J, Buis T, Kirklin JW, Blackstone EA, et al. The arterial switch operation: an eight year experience. J Thorac Cardiovasc Surg 1986;92:36184.

2. Jatene AD, Fontes VF, Paulista PP, Souza LC, Niger F, Galantier $M$, et al. Successful anatomic correction of transposition of great vessels: a preliminary report. Arg Bras Cardiol 1975;28:461-4.

3. Aubert J, Pannetier A, Bouvelly JP, Unal D, Rounault F, De Laure A. Transposition of great arteries: new technique of anatomical correction. Br Heart J 1978;40:204-8.

4. Damus R. Correspondence [letter]. Ann Thorac Surg 1975; 20:724.

5. Kay EB, Cross FS. Surgical treatment of transposition of the great vessels. Surgery 1955;38:712-6. 
6. Stansel HC Jr. A new operation for d-loop transposition of great vessels. Ann Thorac Surg 1975;19:565-7.

7. Yacoub MH, Radley-Smith R. Anatomy of the coronary arteries in transposition of the great arteries and methods for their transfer in anatomical correction. Thorax, 1978;33:41824.

8. Planché C, Bruniaux J, Lacour-Gayet F, Kachaner J, Binet JP, Sidi D, et al. Switch operation for transposition of great arteries in neonates: a study of 120 patients. J Thorac Cardiovasc Surg 1988;96:354-63.
9. Castañeda AR, Norwood WI, Jonas RA, Colon SD, Sandars SP, Lang P. Transposition of the great arteries and intact ventricular septum: anatomical repair in the neonate. Ann Thorac Surg 1984;38:438-43.

10. Takeuchi S, Katogi K. New technique for the arterial switch operation in difficult situations. Ann Thorac Surg 1990;50: 1000-1.

11. Asou T, Karl TR, Plawado A, Mee RB. Arterial switch: translocation of the intramural coronary artery. Ann Thorac Surg 1994;57:461-5.

\section{Bound volumes available to subscribers}

Bound volumes of The Journal of Thoracic and Cardiovascular Surgery are available to subscribers (only) for the 1996 issues from the Publisher, at a cost of $\$ 100.50$ for domestic, $\$ 128.94$ for Canadian, and $\$ 120.50$ for international subscribers for Vol. 111 (January-June) and Vol. 112 (July-December). Shipping charges are included. Each bound volume contains a subject and author index and all advertising is removed. Copies are shipped within 60 days after publication of the last issue of the volume. The binding is durable buckram with the Journal name, volume number, and year stamped in gold on the spine. Payment must accompany all orders. Contact Mosby-Year Book, Inc., Subscription Services, 11830 Westline Industrial Drive, St. Louis, Missouri 63146-3318, USA; phone 800-453-4351 or 314-453-4351.

Subscriptions must be in force to qualify. Bound volumes are not available in place of a regular Journal subscription. 